\title{
The triallelic serotonin transporter gene polymorphism is associated with depressive symptoms in adults with chronic pain
}

This article was published in the following Dove Press journal:

Journal of Pain Research

9 May 2017

Number of times this article has been viewed

\author{
W Michael Hooten' \\ Cynthia O Townsend ${ }^{2}$ \\ Christopher D Sletten ${ }^{3}$ \\ 'Department of Anesthesiology \\ and Perioperative Medicine, Mayo \\ Clinic Rochester, Rochester, MN, \\ ${ }^{2}$ Department of Psychiatry and \\ Psychology, Mayo Clinic Arizona, \\ Scottsdale, AZ, ${ }^{3}$ Department of \\ Pain Medicine, Mayo Clinic Florida, \\ Jacksonville, FL, USA
}

\begin{abstract}
Background: The serotonin (5-HT) transporter-linked polymorphic region (5-HTTLPR) moderates the relationship between stressful life events and depression. Given the high prevalence of depression in chronic pain, the primary aim of this preliminary study was to investigate the associations between the 5-HTTLPR and the severity of depressive symptoms in a cohort of adults with chronic pain.
\end{abstract}

Methods: Adults with chronic pain who were consecutively admitted to an outpatient pain rehabilitation program and met inclusion criteria were recruited for study participation $(n=277)$. Individuals were genotyped for the 5-HTTLPR (including rs25531) and categorized as high, intermediate, or low expressors of the 5-HT transporter. The severity of depressive symptoms at admission was measured by using the Center for Epidemiologic Depression scale (CES-D). Results: The distribution of the high-, intermediate-, and low-expressing genotypes was 61 (22\%), 149 (54\%), and 67 (24\%), respectively. The Hardy-Weinberg $P$-value was 0.204 , which indicated no departure from equilibrium. A main effect of 5-HTTLPR was observed for depressive symptoms $(P=0.040)$ where Center for Epidemiologic Depression scale (CES-D) scores were significantly greater in the low-expressing group compared to the high- $(P=0.019)$ and intermediate $(P=0.029)$-expressing groups. In multivariate multinomial logistic regression analysis adjusted for age, sex, pain severity, pain catastrophizing, and pain anxiety, greater CES-D scores were significantly associated with the 5-HTTLPR low-expressing group compared to the high-expressing group ( $P=0.023$ ), but not for the low-expressing group compared to the intermediate-expressing group $(P=0.056)$.

Conclusion: These preliminary findings suggest that the triallelic 5-HTTLPR could influence the severity of depressive symptoms in adults with chronic pain. Individuals with chronic pain may be particularly vulnerable to the moderating effects of 5-HTTLPR due to high levels of pain-related stress that are inherently present in this population.

Keywords: serotonin transporter gene, chronic pain, depression

\section{Introduction}

The effects of serotonin (5-HT) on depression are influenced, in part, by polymorphisms in the gene (SLC6A4) coding for the 5-HT transporter (5-HTT) which facilitates the reuptake of 5-HT from the synaptic cleft. ${ }^{1}$ This gene has a 43-base-pair (bp) insertiondeletion in the regulatory promoter region referred to as the 5-HT transporter-linked polymorphic region (5-HTTLPR). ${ }^{2,3}$ The short $(S)$ allele has been associated with reduced 5-HTT expression and 5-HT reuptake compared to the long $(L)$ allele. The genetic expression of 5-HTT is further influenced by a single-nucleotide polymorphism
Correspondence: W Michael Hooten Department of Anesthesiology and Perioperative Medicine, Division of Pain Medicine, 200 First St SW, Charlton I-I45, Rochester, MN 55905, USA Tel: +I 5072667692

Email hooten.william@mayo.edu 
(SNP) in the promoter region (A to G substitution; rs25531)., The minor $G$ allele, which is predominately in phase with the $L$ allele, reduces the 5-HTT transcription to $S$ allele levels. When studied together, the 5-HTTLPR and SNP are referred to as the triallelic 5-HTTLPR polymorphism. Based on the level of 5-HTT expression, three distinct levels have been described including a high- $\left(\mathrm{L}_{\mathrm{A}} / \mathrm{L}_{\mathrm{A}}\right)$, intermediate- $\left(\mathrm{S}_{\mathrm{A}} / \mathrm{L}_{\mathrm{A}}\right.$, $\left.\mathrm{L}_{\mathrm{A}} / \mathrm{L}_{\mathrm{G}}\right)$, and low $\left(\mathrm{S}_{\mathrm{A}} / \mathrm{S}_{\mathrm{A}}, \mathrm{L}_{\mathrm{G}} / \mathrm{S}_{\mathrm{A}}\right)$-expressing group. ${ }^{6,7}$ Initial observations of an interaction between the 5-HTTLPR $S$ allele, life stress, and depression were highly scrutinized, ${ }^{8-10}$ but subsequent work suggests that the $S$ allele moderates the relationship between stressful life events and depression. ${ }^{11,12}$

The estimated prevalence of depression exceeds $50 \%-60 \%$ among adults with chronic pain. ${ }^{13}$ The frequent co-occurrence of chronic pain and depressive symptoms reflects, in part, the shared neural circuits that exist between these two health problems. Functional imaging studies support this assertion where alterations in brain regions responsible for processing affective stimuli have been observed in adults with various chronic pain conditions including fibromyalgia, abdominal pain, and low back pain. ${ }^{14-17}$

The interaction between 5-HTTLPR, life stress, and depression combined with the high prevalence of depression in chronic pain suggests that the triallelic 5-HTTLPR polymorphism could influence the severity of depressive symptoms in adults with chronic pain. Although the influence of 5-HTTLPR has been investigated in numerous populations with psychiatric and neurological disorders, ${ }^{11,12}$ the effects of 5-HTTLPR have not been previously reported for a cohort comprised exclusively of adults with chronic pain. Thus, the primary aim of this preliminary study was to investigate the associations between the triallelic 5-HTLLPR polymorphism and the severity of depressive symptoms in a cohort of adults with chronic pain. This represents a secondary analysis of previously published data. ${ }^{18}$

\section{Methods}

\section{Participants}

The study protocol was approved by the Mayo Foundation Institutional Review Board, and written informed consent was provided by all patients prior to study participation. As previously reported, ${ }^{18}$ all adults consecutively admitted to the Mayo Comprehensive Pain Rehabilitation Center from March 2009 to March 2010 were eligible for study recruitment. During this time period, 524 patients were admitted and 300 met inclusion criteria and were successfully recruited. Inclusion criteria included: 1 ) admission to the outpatient pain treatment program; 2) chronic non-cancer pain $>3$ months duration; and 3) age $>18$ years. Exclusion criteria included the presence of a major medical (eg, severe cardiac or pulmonary disease), surgical (eg, spine, intrapelvic, or intraabdominal surgery within 6 months prior to admission), or psychiatric disorder (eg, schizophrenia, dementia) that precluded full participation in the outpatient treatment program. The genotype of one patient could not be determined, and baseline assessments were not obtained for 22 patients. Thus, the study cohort comprised 277 patients.

\section{Study setting}

The clinical setting has been previously described. ${ }^{19}$ Briefly, a cognitive behavioral model served as the basis for treatment, and the primary goal of the outpatient program was restoration of physical and emotional functioning. The outpatient pain rehabilitation program was of 3 weeks duration, and patients attended 8 hours daily. Patients were involved in daily physical and occupational therapy, and all patients attended daily educational group sessions related to management of depressive symptoms, relaxation training, stress management, activity moderation, and elimination of pain behaviors.

\section{Demographic and clinical characteristics}

Baseline demographic and clinical characteristics were collected at admission including age, sex, ethnicity, pain duration, and primary pain site.

\section{Measures}

The self-report questionnaires were completed on the day of admission to the pain rehabilitation program.

\section{Depressive symptoms}

The Center for Epidemiologic Studies Depression (CES-D) scale was used to measure the severity of depressive symptoms. ${ }^{20}$ The 20 -item self-administered questionnaire has established reliability and validity. ${ }^{21,22}$ Total scores range from 0 to 60 , where higher scores indicate greater levels of depressive symptoms.

\section{Pain severity}

Pain severity was assessed by using the pain severity subscale of the Multidimensional Pain Inventory (MPI). ${ }^{23}$ Three questions comprise the pain severity subscale: 1) "Rate the level of your pain at the present moment"; 2) "On the average, how severe has your pain been during the last week"; and 3) "How much suffering do you experience because of your pain." Raw scores were converted to standardized $t$-scores with a normative value of 50 (range, 0-100) and an SD 
of $10 .^{24}$ This self-report questionnaire has proven reliability and construct validity. ${ }^{25}$

\section{Pain catastrophizing}

The Pain Catastrophizing Scale (PCS) assesses the negative cognitions and emotions associated with actual or anticipated pain experiences. ${ }^{26}$ This is a 13 -item self-report questionnaire, with scores ranging from 0 to 52, with higher scores indicating negative expectancies regarding the ability to cope with pain.

\section{Pain anxiety}

Pain anxiety was measured by using the short version of the Pain Anxiety Symptoms Scale (PASS-20). ${ }^{27}$ This is a 20 -item self-report questionnaire, with a score range from 0 to 100 , with higher scores indicating greater levels of pain anxiety.

\section{Genotyping}

As previously reported, ${ }^{18}$ DNA was extracted from whole blood at the Biospecimens Accessioning Processing Laboratory at Mayo Clinic Rochester by using an automated platform (AutoGen FlexStar Qiagen Chemistries, Holliston, MA, USA), quantification was by UV absorbance, and quality was assessed by $260 / 280$ optical density ratio. The simultaneous determination of the long and short form of the 5-HTT promoter region and rs25531 was performed by polymerase chain reaction amplification of the promoter region of 5-HTT followed by Hpa II digestion of the resulting amplicon as described by Wendland et al. ${ }^{5,28}$ Samples were denatured for 1 cycle of 2 minutes at $94^{\circ} \mathrm{C}$, annealed for 30 cycles at $94^{\circ} \mathrm{C}$ for 30 seconds, $58^{\circ} \mathrm{C}$ for 30 seconds, $72^{\circ} \mathrm{C}$ for 1 minute, and elongated for 10 minutes at $72^{\circ} \mathrm{C}$. Digested fragment sizes of 512 and $469 \mathrm{bp}$ correspond to $\mathrm{L}_{\mathrm{A}}$ and $\mathrm{S}_{\mathrm{A}}$ (long or short allele with "A" present at rs25531), respectively. The presence of $G$ at $r s 25531$ is indicative of a digested fragment of $402 \mathrm{bp}$ and an additional fragment of 69 or $100 \mathrm{bp}$ for the short and long allele, respectively.

\section{Statistical analyses}

Demographic, clinical characteristics, and measures of depressive symptoms, pain catastrophizing, and pain anxiety were summarized for the three 5-HTTLPR groups. Mean and standard deviation were reported for continuous variables, and count and proportion were reported for categorical variables. Nonparametric tests (Kruskal-Wallis test) were used to assess the main effects of the 5-HTTLPR groups on depressive symptoms, pain severity, pain catastrophizing, and pain anxiety. Group comparisons were performed separately by using the Mann-Whitney $U$ test when a significant main effect was identified. Univariable and multivariable multinomial logistic regression analyses were performed with the 5-HTTLPR low-expressing group as the comparator (dependent) variable. Independent variables in the multinomial logistic regression model included age, sex, depressive symptoms, pain severity, pain catastrophizing, and pain anxiety. These variables were selected due to previously reported associations with either the 5-HTTLPR ${ }^{29}$ or depressive symptoms ${ }^{30,31}$ in adults with chronic pain. The Hardy-Weinberg equilibrium for genotypic distribution was determined by using the $\chi^{2}$ test for each group. ${ }^{32}$ The level of significance for all tests was set at $P=0.05$, and all analyses were completed by using SPSS (IBM, Inc; Version 21.0, Chicago, IL, USA).

\section{Results}

\section{Sample characteristics}

The demographic and clinical characteristics have been summarized in Table 1. The majority of the study participants were Caucasian females. The three most frequently occurring pain diagnoses were low back pain, fibromyalgia, and generalized pain. The distribution of the high-, intermediate-, and low-expressing genotypes was $61(22 \%), 149(54 \%)$, and 67 (24\%), respectively. The Hardy-Weinberg $P$-value was 0.204 , which indicated no departure from equilibrium. No significant group differences in demographic or clinical characteristics were observed based on the 5-HTTLPR groups.

\section{Depressive symptoms}

Table 2 summarizes the mean scores for the CES-D, MPI pain severity subscale, PCS, and PASS-20. A main effect of 5-HTTLPR was observed for the CES-D $(P=0.040)$. Individual 5-HTTLPR group analyses demonstrated that CES-D scores were significantly greater in the low-expressing group compared to the high-expressing group $(P=0.019)$ (Figure 1). Similarly, CES-D scores were significantly greater in the lowexpressing group compared to the intermediate-expressing group ( $P=0.029)$. No significant difference in CES-D scores was observed between the high- and intermediate-expressing groups.

In univariate multinominal logistic regression analysis with the low-expressing group as the comparator variable, greater CES-D scores were significantly associated with the 5-HTTLPR low-expressing group compared to the highexpressing group $(P=0.032)$ (Table 3$)$. Similarly, greater CES-D scores were significantly associated with the lowexpressing group compared to the intermediate-expressing group ( $P=0.049)$. No significant associations were observed 
Table I Demographic and clinical characteristics of study participants

\begin{tabular}{|c|c|c|c|c|}
\hline \multirow[t]{2}{*}{ Characteristics } & \multirow[t]{2}{*}{ Total $(n=277)$} & \multicolumn{3}{|c|}{ 5-HTTLPR genotype } \\
\hline & & $\begin{array}{l}\text { High expressing } \\
(n=60)\end{array}$ & $\begin{array}{l}\text { Intermediate } \\
(n=149)\end{array}$ & $\begin{array}{l}\text { Low expressing } \\
(n=68)\end{array}$ \\
\hline Age, years, mean $\pm S D$ & $45.5 \pm 13.2$ & $46.9 \pm 12.7$ & $45.6 \pm 13.3$ & $44.1 \pm 13.4$ \\
\hline Sex, number of female (\%) & $185(67)$ & $44(72)$ & $98(66)$ & $43(64)$ \\
\hline Ethnicity, Caucasian, n (\%) & $263(95)$ & $57(93)$ & $145(97)$ & $61(91)$ \\
\hline Pain duration, years, mean $\pm S D$ & $9.3 \pm 8.3$ & $8.5 \pm 9.0$ & $9.7 \pm 7.9$ & $9.0 \pm 8.6$ \\
\hline \multicolumn{5}{|l|}{ Primary pain diagnosis } \\
\hline Low back pain, n (\%) & $62(22)$ & $9(15)$ & $32(21)$ & $2 I(3 I)$ \\
\hline Fibromyalgia & $60(23)$ & $13(21)$ & $32(21)$ & $15(22)$ \\
\hline Abdominal & $21(8)$ & $9(15)$ & $8(5)$ & $4(6)$ \\
\hline Generalized & $37(13)$ & $7(11)$ & $23(15)$ & $7(10)$ \\
\hline Chronic headache & $28(10)$ & $4(7)$ & $18(12)$ & $6(9)$ \\
\hline Pelvic & $10(4)$ & $2(3)$ & $7(5)$ & I (2) \\
\hline Lower extremity & $15(5)$ & $4(6)$ & $7(5)$ & $4(6)$ \\
\hline Facial & $5(2)$ & $I(2)$ & $3(2)$ & $\mathrm{I}(2)$ \\
\hline Neck & $21(7)$ & $7(13)$ & II (7) & $3(3)$ \\
\hline Upper extremity & $13(5)$ & $3(5)$ & $7(5)$ & $3(4)$ \\
\hline Chest wall & $3(1)$ & 0 & $\mathrm{I}(<\mathrm{I})$ & $2(3)$ \\
\hline Other & $2(<1)$ & I (2) & 0 & I (2) \\
\hline
\end{tabular}

Abbreviations: SD, standard deviation; HTTLPR, (5-HT) transporter-linked polymorphic region.

Table 2 Mean values $( \pm S D)$ of depressive symptoms, pain severity, pain catastrophizing, and pain anxiety

\begin{tabular}{llllll}
\hline Variables & $\begin{array}{l}\text { Total } \\
(\mathbf{n = 2 7 7})\end{array}$ & $\begin{array}{l}\text { High expressing } \\
(\mathbf{n = 6 0 )}\end{array}$ & $\begin{array}{l}\text { Intermediate } \\
(\mathbf{n = 1 4 9 )}\end{array}$ & $\begin{array}{l}\text { Low expressing } \\
(\mathbf{n = 6 8 )}\end{array}$ \\
\hline Depressive symptoms & $28.8 \pm 12.7$ & $27.0 \pm 12.1$ & $28.2 \pm 13.5$ & $31.9 \pm 10.9$ & 0.040 \\
Pain severity & $51 \pm 7.1$ & $50.3 \pm 7.4$ & $51.0 \pm 7.1$ & $51.4 \pm 6.7$ & 0.863 \\
Pain catastrophizing & $27.4 \pm 11.3$ & $26.7 \pm 10.4$ & $27.0 \pm 11.8$ & $28.7 \pm 10.9$ & 0.495 \\
Pain anxiety & $49.1 \pm 19.4$ & $47.7 \pm 16.6$ & $49.1 \pm 20.4$ & $50.2 \pm 19.4$ & 0.877 \\
\hline
\end{tabular}

Notes: *Kruskal-Wallis test. Depressive symptoms, Centers for Epidemiologic Studies Depression scale; pain severity, Multidimensional Pain Inventory pain severity subscale; pain catastrophizing, Pain Catastrophizing Scale; pain anxiety, Pain Anxiety Symptoms Scale.

Abbreviation: SD, standard deviation.

between the 5-HTTLPR groups and age, sex, pain severity, pain catastrophizing, or pain anxiety.

In multivariate multinomial logistic regression analysis adjusted for age, sex, pain severity, pain catastrophizing, and pain anxiety, the significant association between greater CES-D scores and the 5-HTTLPR low-expressing group was retained $(P=0.023)$ (Table 3$)$. However, the association between greater CES-D scores and the 5-HTTLPR intermediate-expressing group was not statistically significant $(P=0.056)$. No significant associations were observed between the 5-HTTLPR groups and age, sex, pain severity, pain catastrophizing, or pain anxiety.

\section{Discussion}

The main finding of this preliminary study was that depressive symptoms were significantly greater in the low-expressing 5-HTTLPR group compared to the high- and intermediateexpressing groups. In multivariate multinominal logistic regression analysis adjusted for age, sex, pain severity, pain catastrophizing, and pain anxiety, the low-expressing group was associated with greater CES-D scores compared to the high-expressing group. These observations suggest that the 5-HTTLPR genotype influenced the severity of depressive symptoms in this study population comprised exclusively of adults with chronic pain.

The observed associations between 5-HTTLPR and depressive symptoms in the absence of a direct measure of life stress warrants further explanation. In 2003, Caspi et $\mathrm{l}^{8}$ reported that the 5-HTTLPR polymorphism moderated the influence of life stress on depression. Specifically, individuals homozygous for the $S$ allele experienced greater levels of depressive symptoms, an increased rate of major depression, and elevated suicidality in response to stressful life events compared to individuals homozygous for the $L$ allele. However, as observed by Karg et al, ${ }^{11}$ evidence supporting a moderation effect was stronger for chronic stressors compared to acute stressors. This observation is relevant to our study population because chronic pain has been identified as an important source of chronic stress. ${ }^{33}$ Thus, 


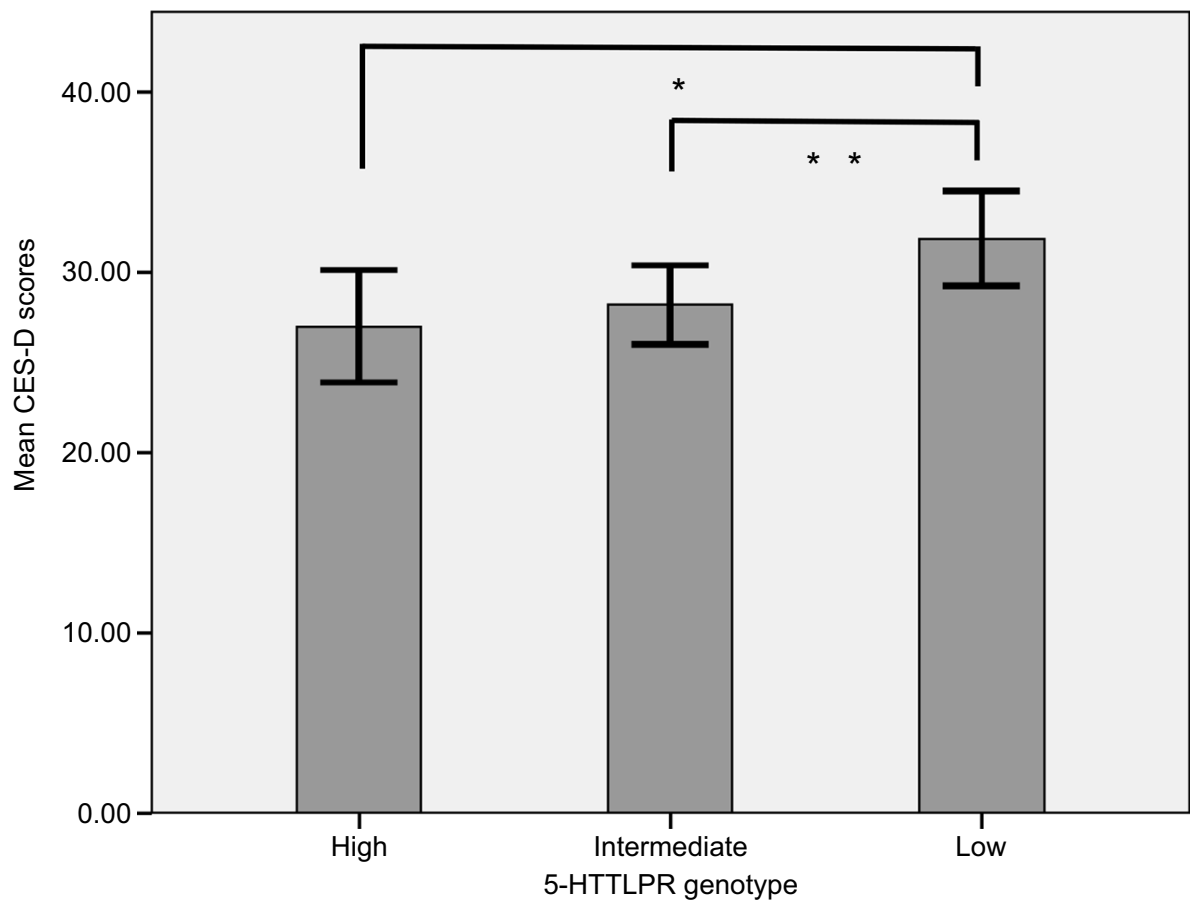

Figure I Mean and standard deviation for Center for Epidemiologic Studies Depression scale scores for each 5-HTTLPR genotype group (Mann-Whitney U test; *P=0.0I9; $* * P=0.029)$.

Abbreviations: HTTLPR, (5-HT) transporter-linked polymorphic region; CES-D, Center for Epidemiologic Depression scale.

Table 3 Univariable and multivariable multinomial logistic regression analysis with the 5-HTTLPR low-expressing genotype as the comparator variable

\begin{tabular}{|c|c|c|c|c|c|c|}
\hline \multirow[t]{2}{*}{ Variables } & \multicolumn{3}{|c|}{ Univariable OR } & \multicolumn{3}{|c|}{ Multivariable OR* } \\
\hline & OR & $95 \% \mathrm{Cl}$ & $P$-value & OR & $95 \% \mathrm{Cl}$ & $P$-value \\
\hline \multicolumn{7}{|c|}{ High- versus low-expressing group } \\
\hline Depressive symptoms & 1.03 & 1.01 to 1.06 & 0.032 & 1.05 & 1.01 to 1.09 & 0.023 \\
\hline Age & 1.02 & 0.99 to 1.04 & 0.224 & 1.02 & 0.99 to 1.04 & 0.264 \\
\hline Female sex & 0.62 & 0.29 to 1.33 & 0.223 & 0.46 & 0.20 to 1.04 & 0.063 \\
\hline Pain severity & 0.98 & 0.95 to 1.03 & 0.387 & 0.99 & 0.94 to 1.05 & 0.794 \\
\hline Pain catastrophizing & 0.98 & 0.95 to 1.02 & 0.328 & 1.01 & 0.95 to 1.07 & 0.735 \\
\hline Pain anxiety & 0.99 & 0.976 to 1.01 & 0.478 & 1.01 & 0.98 to 1.04 & 0.650 \\
\hline \multicolumn{7}{|l|}{ Intermediate versus low } \\
\hline Depressive symptoms & 1.02 & 1.00 to 1.05 & 0.049 & 1.03 & 0.99 to 1.07 & 0.056 \\
\hline Age & 1.01 & 0.99 to 1.03 & 0.448 & 1.01 & 0.98 to 1.03 & 0.625 \\
\hline Female sex & 0.89 & 0.49 to 1.62 & 0.716 & 0.82 & 0.43 to 1.53 & 0.525 \\
\hline Pain severity & 0.99 & 0.95 to 1.03 & 0.717 & 1.00 & 0.96 to 1.05 & 0.880 \\
\hline Pain catastrophizing & 0.99 & 0.96 to 1.01 & 0.307 & 0.99 & 0.95 to 1.04 & 0.767 \\
\hline Pain anxiety & 1.00 & 0.98 to 1.01 & 0.721 & 1.01 & 0.99 to 1.04 & 0.337 \\
\hline
\end{tabular}

Notes: *Adjusted for all other factors listed in the table. Depressive symptoms, Centers for Epidemiologic Studies Depression scale; pain severity, Multidimensional Pain Inventory pain severity subscale; pain catastrophizing, Pain Catastrophizing Scale; pain anxiety, Pain Anxiety Symptoms Scale.

Abbreviations: HTTLPR, (5-HT) transporter-linked polymorphic region; Cl, confidence interval; OR, odds ratio.

the association between the 5-HTTLPR low-expressing group and depressive symptoms observed herein was possibly due, in part, to high levels of chronic stress that were inherently present in our study population. This supposition is further supported by numerous epidemiologic studies that report the estimated prevalence of posttraumatic stress disorder in adults with chronic pain exceeds $20 \% .{ }^{3440}$ Collectively, these data suggest that individuals with chronic pain, including those without current depression, may be particularly vulnerable to the moderating effects of 5-HTTLPR due to high levels of chronic stress.

The CES-D has been used in numerous 5-HTTLPR association studies, but the results have been mixed. For example, in a study that involved 177 Japanese health care workers ${ }^{41}$ and a study that involved 698 African-American women, ${ }^{42}$ CES-D scores were significantly greater among 
individuals with the $S$ allele compared to the other allelic groups. In a study of 984 Taiwanese adults, "extreme" traumatic stressors, but not stressful life events, were associated with greater CES-D scores among individuals with the $S$ allele. ${ }^{43}$ However, in three separate studies that reported data from 306 Chinese adults with Parkinson's disease, ${ }^{44} 568$ white non-Hispanic women, ${ }^{45}$ and 1421 individuals from a "French community," ${ }^{46}$ no significant associations were found between the 5-HTTLPR polymorphism, life stress, or CES-D scores. Furthermore, two studies reported an opposite association where the $L$ allele was observed to moderate the effects of life stress on depressive symptoms as measured by the CES-D. ${ }^{47,48}$ The association of 5-HTTLPR with depressive symptoms and life stress has been reported to vary by sex in two studies that used the CES-D. ${ }^{49,50}$ Although evidence supporting sex differences in the moderating effects of 5-HTTLPR on depression exists, ${ }^{29,51}$ no significant effect of 5-HTTLPR on sex was observed in the present study.

The observations from this preliminary study have several implications for future research. First, the findings of this study need to be replicated by using validated measures of acute and chronic life stress. This would allow investigators to test the hypothesis that the susceptibility of adults with chronic pain to depression is partly influenced by the moderating effects of 5-HTTLPR. Second, following the replication of findings of the study, prospective trials could investigate the potential effects of cognitive behavioral interventions aimed specifically at enhancing stress management in an attempt to mitigate the moderating effects of the 5-HTTLPR low-expressing genotype. In this particular subgroup of patients, enhancing the capacity for stress management could yield improvements in depression beyond the therapeutic effects associated with depression-specific CBT interventions. ${ }^{52}$ Third, prospective trials could also be designed to assess the efficacy of analgesic antidepressant medications in association with 5-HTTLPR in adults with chronic pain. Although the associations between serotonin norepinephrine reuptake inhibitors, tricyclic antidepressants, and 5-HTTLPR have been reported, these trials were conducted in various populations of adults with primary psychiatric disorders. ${ }^{53}$

This study has limitations. The demographic and clinical characteristics of individuals referred for multidisciplinary pain rehabilitation at a tertiary referral medical center may vary compared to a random community sample of adults with chronic pain. This could limit the generalization of the findings of this study. However, as previously reported, ${ }^{18}$ in a study that involved a random sample of adults with chronic pain living in the catchment area of our institution,
$96 \%$ were white and $56 \%$ were female. ${ }^{54}$ Despite these demographic similarities, the risk of referral bias cannot be excluded, and the observed associations between 5-HTTLPR and depressive symptoms may not be applicable to other populations of adults with chronic pain. Although the CES-D was used to measure the severity of depressive symptoms, the participants of the study did not undergo a formal diagnostic evaluation for a mood disorder. Finally, a validated measure of life stress was not available, which limits further analysis of a possible gene by environment interaction.

\section{Conclusion}

In this preliminary study that involved a cohort of adults with chronic pain, the 5-HTTPR had a significant effect on the severity of depressive symptoms as measured by the CES-D. The observations from this study suggest that future research is warranted in order to further characterize the moderating effects of 5-HTTLPR on chronic pain-related stress and depressive symptoms.

\section{Disclosure}

The authors report no conflicts of interest in this work.

\section{References}

1. Kambeitz JP, Howes OD. The serotonin transporter in depression: metaanalysis of in vivo and post mortem findings and implications for understanding and treating depression. J Affect Disord. 2015;186:358-366.

2. Heils A, Teufel A, Petri S, et al. Allelic variation of human serotonin transporter gene expression. J Neurochem. 1996;66:2621-2624.

3. Ramamoorthy S, Bauman AL, Moore KR, et al. Antidepressant- and cocaine-sensitive human serotonin transporter: molecular cloning, expression, and chromosomal localization. Proc Natl Acad Sci USA. 1993;90:2542-2546.

4. Hu X, Oroszi G, Chun J, Smith TL, Goldman D, Schuckit MA. An expanded evaluation of the relationship of four alleles to the level of response to alcohol and the alcoholism risk. Alcohol Clin Exp Res. 2005; 29:8-16.

5. Wendland JR, Martin BJ, Kruse MR, Lesch KP, Murphy DL. Simultaneous genotyping of four functional loci of human SLC6A4, with a reappraisal of 5-HTTLPR and rs25531. Mol Psychiatry. 2006;11:224-226.

6. Lesch KP, Bengel D, Heils A, et al. Association of anxiety-related traits with a polymorphism in the serotonin transporter gene regulatory region. Science. 1996;274:1527-1531.

7. Murphy DL, Lesch KP. Targeting the murine serotonin transporter: insights into human neurobiology. Nat Rev Neurosci. 2008;9:85-96.

8. Caspi A, Sugden K, Moffitt TE, et al. Influence of life stress on depression: moderation by a polymorphism in the 5-HTT gene. Science. 2003; 301:386-389.

9. Risch N, Herrell R, Lehner T, et al. Interaction between the serotonin transporter gene (5-HTTLPR), stressful life events, and risk of depression: a meta-analysis. JAMA. 2009;301:2462-2471.

10. Munafo MR, Durrant C, Lewis G, Flint J. Gene $\times$ environment interactions at the serotonin transporter locus. Biol Psychiatry. 2009;65: 211-219.

11. Karg K, Burmeister M, Shedden K, Sen S. The serotonin transporter promoter variant (5-HTTLPR), stress, and depression meta-analysis revisited: evidence of genetic moderation. Arch Gen Psychiatry. 2011;68:444-454. 
12. Sharpley CF, Palanisamy SK, Glyde NS, Dillingham PW, Agnew LL. An update on the interaction between the serotonin transporter promoter variant (5-HTTLPR), stress and depression, plus an exploration of nonconfirming findings. Behav Brain Res. 2014;273:89-105.

13. Hooten WM. Chronic pain and mental health disorders: shared neural mechanisms, epidemiology, and treatment. Mayo Clin Proc. 2016;91: 955-970.

14. Baliki MN, Chialvo DR, Geha PY, et al. Chronic pain and the emotional brain: specific brain activity associated with spontaneous fluctuations of intensity of chronic back pain. J Neurosci. 2006;26:12165-12173.

15. Berman SM, Naliboff BD, Suyenobu B, et al. Reduced brainstem inhibition during anticipated pelvic visceral pain correlates with enhanced brain response to the visceral stimulus in women with irritable bowel syndrome. J Neurosci. 2008;28:349-359.

16. Hashmi JA, Baliki MN, Huang L, et al. Shape shifting pain: chronification of back pain shifts brain representation from nociceptive to emotional circuits. Brain. 2013;136:2751-2768.

17. Jensen KB, Kosek E, Petzke F, et al. Evidence of dysfunctional pain inhibition in fibromyalgia reflected in $\mathrm{ACC}$ during provoked pain. Pain. 2009;144:95-100.

18. Hooten WM, Hartman WR, Black JL, 3rd, Laures HJ, Walker DL. Associations between serotonin transporter gene polymorphisms and heat pain perception in adults with chronic pain. BMC Med Genet. 2013;14:78.

19. Townsend CO, Bruce BK, Hooten WM, Rome JD. The role of mental health professionals in multidisciplinary pain rehabilitation programs. J Clin Psychol. 2006;62:1433-1443.

20. Radloff L. A self-report depression scale for research in the general population. Appl Psychol Meas. 1977;1:385-401.

21. Geisser ME, Roth RS, Robinson ME. Assessing depression among persons with chronic pain using the Center for Epidemiological StudiesDepression Scale and the Beck Depression Inventory: a comparative analysis. Clin J Pain. 1997;13:163-170.

22. Weissman MM, Sholomskas D, Pottenger M, Prusoff BA, Locke BZ Assessing depressive symptoms in five psychiatric populations: a validation study. Am J Epidemiol. 1977;106:203-214.

23. Kerns RD, Turk DC, Rudy TE. The West Haven-Yale Multidimensional Pain Inventory (WHYMPI). Pain. 1985;23:345-356.

24. Rudy TE. Rudy TE. Multiaxial Assessment of Multidimensional Pain Inventory: Computer Program User's Manual. Pittsburgh, PA: University of Pittsburgh; 1989.

25. Bernstein IH, Jaremko ME, Hinkley BS. On the utility of the West HavenYale Multidimensional Pain Inventory. Spine (Phila Pa 1976). 1995; 20:956-963.

26. Sullivan M, Pivik J. The Pain Castrophizing Scale: development and validation. Psychol Assess. 1995;7:524-532.

27. McCracken LM, Dhingra L. A short version of the Pain Anxiety Symptoms Scale (PASS-20): preliminary development and validity. Pain Res Manag. 2002;7:45-50

28. Wendland JR, Moya PR, Kruse MR, et al. A novel, putative gain-offunction haplotype at SLC6A4 associates with obsessive-compulsive disorder. Hum Mol Genet. 2008;17:717-723.

29. Gressier F, Calati R, Serretti A. 5-HTTLPR and gender differences in affective disorders: a systematic review. J Affect Disord. 2016;190 193-207.

30. Kadimpati S, Zale EL, Hooten WM, Ditre JW, Warner DO. Correction: associations between neuroticism and depression in relation to catastrophizing and pain-related anxiety in chronic pain patients. PLoS One. 2015;10:e0129871.

31. Darchuk KM, Townsend CO, Rome JD, Bruce BK, Hooten WM. Longitudinal treatment outcomes for geriatric patients with chronic non-cancer pain at an interdisciplinary pain rehabilitation program. Pain Med. 2010;11:1352-1364.

32. Weir BS. Genetic data analysis II: methods for discrete population genetic data. Sunderland, MA: Sinauer Associates, Inc.; 1997.

33. Hannibal KE, Bishop MD. Chronic stress, cortisol dysfunction, and pain: a psychoneuroendocrine rationale for stress management in pain rehabilitation. Phys Ther. 2014;94:1816-1825.
34. Demyttenaere K, Bruffaerts R, Lee S, et al. Mental disorders among persons with chronic back or neck pain: results from the World Mental Health Surveys. Pain. 2007;129:332-342.

35. McWilliams LA, Cox BJ, Enns MW. Mood and anxiety disorders associated with chronic pain: an examination in a nationally representative sample. Pain. 2003;106:127-133.

36. Reme SE, Tangen T, Moe T, Eriksen HR. Prevalence of psychiatric disorders in sick listed chronic low back pain patients. Eur J Pain. 2011;15: 1075-1080.

37. Stang PE, Brandenburg NA, Lane MC, Merikangas KR, Von Korff MR, Kessler RC. Mental and physical comorbid conditions and days in role among persons with arthritis. Psychosom Med. 2006;68:152-158.

38. Uguz F, Cicek E, Salli A, et al. Axis I and Axis II psychiatric disorders in patients with fibromyalgia. Gen Hosp Psychiatry. 2010;32:105-107.

39. Von Korff M, Crane P, Lane M, et al. Chronic spinal pain and physicalmental comorbidity in the United States: results from the national comorbidity survey replication. Pain. 2005;113:331-339.

40. Arnold LM, Hudson JI, Keck PE, et al. Comorbidity of fibromyalgia and psychiatric disorders. J Clin Psychiatry. 2006;67:1219-1225.

41. Tsuboi H, Sakakibara H, Yamakawa-Kobayashi K, et al. Val1483Ile polymorphism in the fatty acid synthase gene was associated with depressive symptoms under the influence of psychological stress. J Affect Disord. 2011;134:448-452.

42. Scheid JM, Holzman CB, Jones N, et al. Life stressors and 5-HTTLPR interaction in relation to midpregnancy depressive symptoms among African-American women. Psychiatr Genet. 2011;21:271-280.

43. Goldman N, Glei DA, Lin YH, Weinstein M. The serotonin transporter polymorphism (5-HTTLPR): allelic variation and links with depressive symptoms. Depress Anxiety. 2010;27:260-269.

44. Zhang JL, Yang JF, Chan P. No association between polymorphism of serotonin transporter gene and depression in Parkinson's disease in Chinese. Neurosci Lett. 2009;455:155-158.

45. Scheid JM, Holzman CB, Jones N, et al. Depressive symptoms in midpregnancy, lifetime stressors and the 5-HTTLPR genotype. Genes Brain Behav. 2007;6:453-464.

46. Power T, Stewart R, Ancelin ML, Jaussent I, Malafosse A, Ritchie K. 5-HTTLPR genotype, stressful life events and late-life depression: no evidence of interaction in a French population. Neurobiol Aging. 2010; 31:886-887.

47. Phillips-Bute B, Mathew JP, Blumenthal JA, et al; Safety Outcomes Investigative $\mathrm{T}$. Relationship of genetic variability and depressive symptoms to adverse events after coronary artery bypass graft surgery. Psychosom Med. 2008;70:953-959.

48. Ritchie K, Jaussent I, Stewart Ret al. Association of adverse childhood environment and 5-HTTLPR genotype with late-life depression. J Clin Psychiatry. 2009;70:1281-1288.

49. Beaver KM, Vaughn MG, Wright JP, Delisi M. An interaction between perceived stress and 5HTTLPR genotype in the prediction of stable depressive symptomatology. Am J Orthopsychiatry. 2012;82:260-266.

50. Brummett BH, Boyle SH, Siegler IC, et al. Effects of environmental stress and gender on associations among symptoms of depression and the serotonin transporter gene linked polymorphic region (5-HTTLPR). Behav Genet. 2008;38:34-43.

51. Perry LM, Goldstein-Piekarski AN, Williams LM. Sex differences modulating serotonergic polymorphisms implicated in the mechanistic pathways of risk for depression and related disorders. $J$ Neurosci Res. 2017;95:737-762.

52. Pence LE, Thorn BE, Davis AM. Cognitive coping strategies in pain management. In: Ebert MH, Kerns RD, editors. Behavioral and Psychopharmacologic Pain Management. Cambridge, UK: Cambridge University Press; 2011:214-235.

53. Porcelli S, Fabbri C, Serretti A. Meta-analysis of serotonin transporter gene promoter polymorphism (5-HTTLPR) association with antidepressant efficacy. Eur Neuropsychopharmacol. 2012;22:239-258.

54. Watkins EA, Wollan PC, Melton LJ, 3rd, Yawn BP. A population in pain: report from the Olmsted County health study. Pain Med. 2008;9: $166-174$. 
The Journal of Pain Research is an international, peer reviewed, open access, online journal that welcomes laboratory and clinical findings in the fields of pain research and the prevention and management of pain. Original research, reviews, symposium reports, hypothesis formation and commentaries are all considered for publication.
The manuscript management system is completely online and includes a very quick and fair peer-review system, which is all easy to use. Visit http://www.dovepress.com/testimonials.php to read real quotes from published authors. 